\title{
Melt-layer thickness measurements during crushing experiments on fresh-water ice
}

\author{
R. E. GAGNON \\ Institute for Marine Dynamics, National Research Council of Canada, St. John's, Newfoundland A1B 3T5, Canada
}

\begin{abstract}
A stainless-steel platen, with a centrally located pressure sensor on the front face, has been used to crush mono-crystalline, bubble-free fresh-water ice samples. Two electrical conductors, located on the face of the pressure sensor, were connected to a bridge circuit so that the presence of liquid between the two conductors could be detected and its thickness measured. Video records of the ice/ steel contact zone during crushing were obtained by mounting samples on a thick Plexiglas plate which permitted viewing through the specimen to the ice/steel interface. Total load and pressure records exhibited a sawtooth pattern due to the compliance of the ice and the testing apparatus, and spalling of ice from the contact zone. When the region of contact was in the vicinity of the pressure transducer, liquid was detected and peaks occurred in the liquid sensor output when load drops occurred. Contact between the platen and the ice consisted of low pressure zones of highly damaged crushed and/or refrozen ice, opaque in appearance, and transparent, high-pressure regions of relatively undamaged ice. Upper limits for the liquid-layer thickness on the high-pressure undamaged ice were $\sim 3 \mu \mathrm{m}$ on the ascending sides of the sawteeth in the load records and $\sim 21 \mu \mathrm{m}$ on the sharp descending sides.
\end{abstract}

\section{INTRODUCTION}

In recent years the processes involved in ice impacts and crushing have been the focus of several investigations (e.g. Määttänen, 1983; Michel and Blanchet, 1983; Evans and others, 1984; Sodhi and Morris, 1984; Timco and Jordaan, 1988; Gagnon and Mølgaard, 1991; Gagnon and Sinha, 1991). These studies are relevant to understanding ice/structure interactions associated with the production of offshore resources, and ice/ship interactions related to transportation on ice-covered waters. The investigations include visual observations of the contact between the ice and the crushing instrument during crushing (Riska and others, 1990; Fransson and others, 1991; Gagnon and Mølgaard, 1991). In the recent work of Gagnon and Mølgaard (1991) and Gagnon and Sinha (1991) it has been shown that pressure melting and generation of heat by viscous flow of the melt is an important mechanism. This paper reports visual records and measurements of pressure and load at the ice/ indentor interface that verify previous reported results and interpretation. In addition, a novel method has been used to detect the presence and thickness of liquid water between the pressure sensor and the ice by monitoring the conductance across a gap between two conductors on the face of the pressure sensor. Electrical signals, caused by spalling of ice in the vicinity of the conductance sensor, were also detected and a full report will be given in the near future.

\section{APPARATUS}

Figure 1 shows the ice-specimen mounting holder. It consisted of a $5 \mathrm{~cm} \times 13 \mathrm{~cm} \times 17 \mathrm{~cm}$ Plexiglas plate on which the ice samples sat. Confining plates for the sides of the specimen were bolted to the Plexiglas. The Plexiglas plate was reinforced to minimize flexure by a $4 \mathrm{~cm}$ thick stainless-steel rectangular backing structure which ran around the perimeter of the upper face of the Plexiglas plate. The reinforced plate was supported on opposite sides by two pillars of aluminum, $12.5 \mathrm{~cm} \times 8 \mathrm{~cm} \times$ $2.5 \mathrm{~cm}$. A cross member attached to the top of the pillars

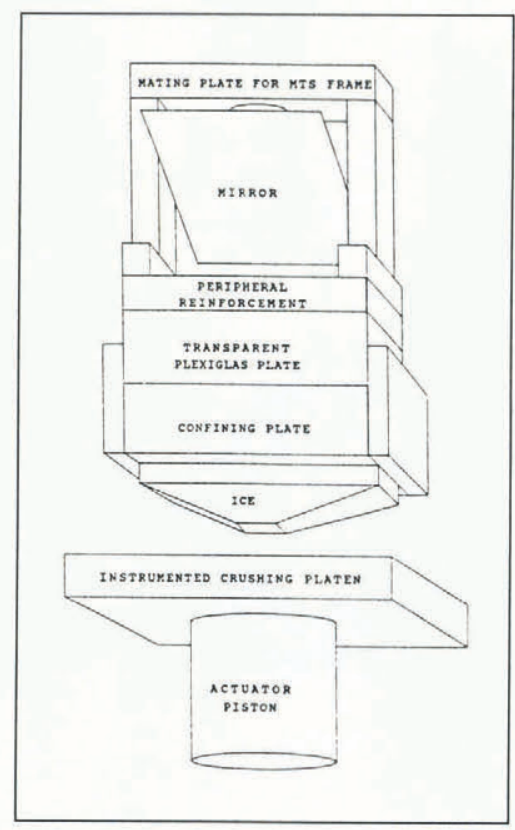

Fig. 1. Crushing apparatus with mirror for viewing the contact zone during experiments. 
mated with the load cell of the testing frame. Between the pillars, a mirror was situated at a $45^{\circ}$ angle so that a video camera could view from the side through the Plexiglas and ice to the region of contact between the ice and the steel loading platen. A flood lamp was used to illuminate the ice and platen along the same view path by placing it beside the video camera. The apparatus was mounted on an MTS frame in a cold room maintained at $-10^{\circ} \mathrm{C}$.

The $4 \mathrm{~cm} \times 20 \mathrm{~cm} \times 20 \mathrm{~cm}$ platen, which the ice was crushed against, was made of stainless steel and instrumented with a piston/diaphragm-type pressure transducer. A conducting wire was installed in the piston of the pressure sensor by drilling and tapping a small hole $(\sim 4 \mathrm{~mm})$ through the piston into which the wire was inserted until it protruded slightly near the center of the hole, and then filling the hole with electrically insulating 5 min epoxy resin (Fig. 2). When the epoxy resin had set, the protruding part was sanded off so the wire tip was flush with the surface of the piston. This served as the liquid sensor. The diameter of the pressure transducer was $8 \mathrm{~mm}$. Total load was monitored by a load cell attached to the cross-head of the loading frame.

To detect the presence of liquid on the sensor, leads from the wire embedded in the epoxy resin and the surrounding piston metal were placed in parallel with one of the resistors of a bridge circuit. The fixed resistors were chosen to optimize the sensitivity of the bridge when resistances in the order of megohms appeared across the gap of the sensor. The bridge was excited with a $205 \mathrm{~V}$ supply and the output was amplified by a factor of 20 . A high excitation voltage was used for the bridge because preliminary ice-crushing tests of the system using a $10 \mathrm{~V}$ excitation revealed that electrical signals created by fracturing of ice in the vicinity of the sensor swamped the signals associated with the liquid detection. Though still present, the relative amplitude of the signals from the cracks compared to those from the liquid sensor was greatly reduced with the higher excitation and the two types of signals were easily distinguishable due to their characteristic shapes.

The liquid-layer sensor was calibrated at room temperature in the following way. The piston of the

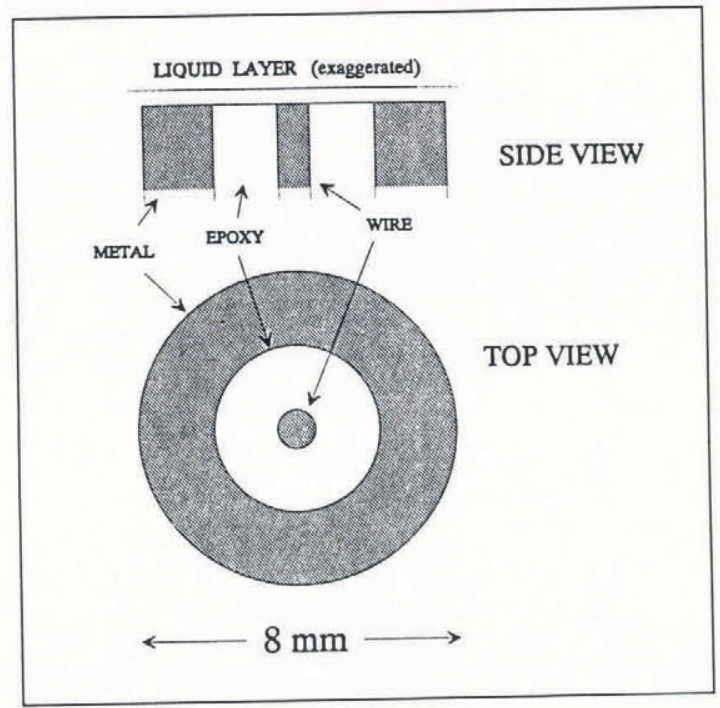

Fig. 2. Schematic of the liquid sensor and pressure transducer.

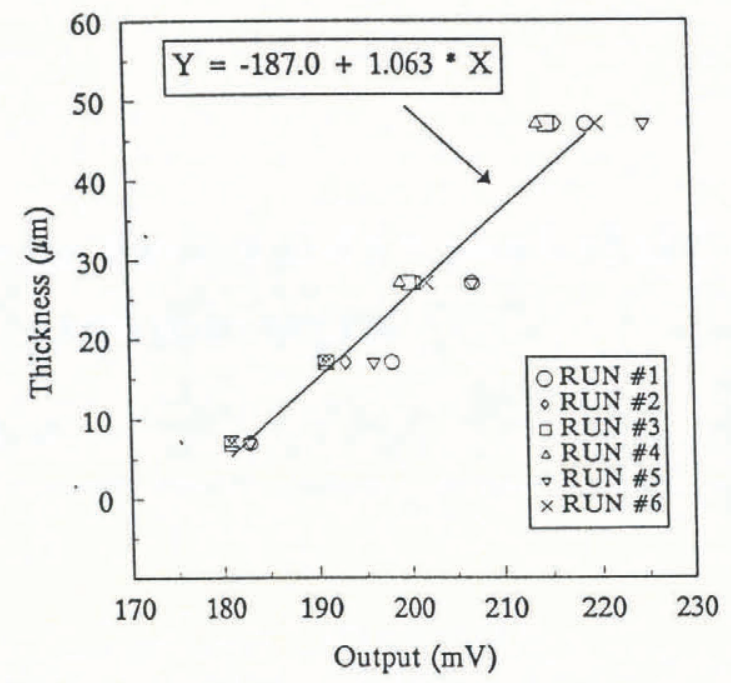

Fig. 3. Calibration data used to convert the output from the liquid sensor to layer thicknesses.

pressure/conductance sensor was carefully aligned in a micrometer jig so that its sensing face was parallel with the flat face of the shaft of the micrometer. A small piece of Mylar was fastened to the end of the micrometer shaft to insulate it electrically from the conductance sensor. A drop of distilled, filtered water with a conductivity of $\sim 1.1 \mu \mathrm{mhos} \mathrm{cm}^{-1}$ at $20^{\circ} \mathrm{C}$ was carefully placed on the sensor using a syringe and ensuring that no tiny air bubbles adhered to the sensor surface within the water droplet. The micrometer shaft was brought into contact with the water and the liquid-filled gap closed to $\sim 50 \mu \mathrm{m}$. The output from the conductance bridge was then recorded as a function of separation as the liquidfilled gap between the end of the micrometer shaft and the sensor was decreased from 47 to $7 \mu \mathrm{m}$. The data from six runs are shown in Figure 3. The output of the sensor was a linear function of the layer thickness and the correlation factor for the fit was 0.97 .

It was assumed that the conductivity of the meltwater produced during the crushing experiments was constant, regardless of the effect of pressure on melting temperature. No data on the effect of pressure on the conductivity of fresh water were available in the literature. However, the data of Bradshaw and Schleicher (1980), on the influence of pressure on the conductivity of saline water of various concentrations in the range $2-35 \%$, were used to obtain an expression for the magnitude of the pressure effect (to $100 \mathrm{MPa}$ ) on conductivity as a function of salinity. Extrapolating this expression to the salinity of the meltwater in the present tests indicated an increase in conductivity of $\sim 14 \%$ for a $100 \mathrm{MPa}$ pressure change. The conductivity of the water used to grow the ice was measured at several temperatures in the range $0-15^{\circ} \mathrm{C}$ and found to increase by $\sim 2.4 \%{ }^{\circ} \mathrm{C}^{-1}$. A $100 \mathrm{MPa}$ pressure change, according to the Clausius-Clapeyron equation, would lower the melting temperature of ice from $0^{\circ}$ to $\sim-7^{\circ} \mathrm{C}$. The temperature effect would give the meltwater produced at $-7^{\circ} \mathrm{C}$ a conductivity $\sim 17 \%$ lower than meltwater at $0^{\circ} \mathrm{C}$. Hence, the effects of the change in pressure and associated melting temperature tend to cancel each other, within a few per cent. The meltwater from the ice used in the present experiments, at $0^{\circ} \mathrm{C}$, had a conductivity approxi- 
mately the same as the water used to calibrate the liquid sensor at room temperature.

Data from the crushing experiments were acquired using a Data Translation analog to digital acquisition board with a throughput of 150000 samples $\mathrm{s}^{-1}$ with 12 bit resolution. This was used in conjunction with a Dell 486 computer. The software package Viewdac (KeithleyAsyst) was used to control the acquisition board and to analyze the data. 80000 samples were acquired from each channel per test at a sampling rate of 20850 samples s $^{-1}$. All tests were run at a fixed nominal actuator speed of $0.5 \mathrm{~cm} \mathrm{~s}^{-1}$.

The video-recording system consisted of a Sony Hi8 camcorder running at 30 frames s$^{-1}$ with a shutter speed of $1 / 2000$ s for all tests. The video records were analyzed with the assistance of a frame-grabber board (Targa M8 (Truevision)) and Java (Jandel) video-analysis software.

\section{SAMPLE PREPARATION}

The method of visual observation of the crushing process at the ice-indentor interface was similar to that described by Gagnon and Mølgaard (1991) and Gagnon (in press), that is, to make use of the transparency of the ice to view the process by looking through the ice specimen. In this case, samples were cut from large single crystals of bubble-free, fresh-water ice with the $c$ axis vertical. The specimens were blocks initially $13 \mathrm{~cm} \times 13 \mathrm{~cm} \times 10 \mathrm{~cm}$ with the top part trimmed to the shape of a truncated pyramid with a slope of $\sim 40^{\circ}$. Sharp edges and corners were rounded by melting and the very top of the peak was smoothed, by rubbing with a glove, to prevent premature cracking at low loads. Single-crystal specimens were used to guarantee good visual observation by eliminating obscuring reflections off grain boundaries, and also crack formation associated with grain boundaries which would block the view. Specimens were mounted on the thick $(5 \mathrm{~cm})$ Plexiglas plate by heating the plate's surface to just above $0^{\circ} \mathrm{C}$ and placing the sample (pre-warmed to $0^{\circ} \mathrm{C}$ ) on to it, causing the ice to melt slightly and match the plate surface exactly. After wiping off excess water the Plexiglas and ice were then put into the cold room at $-10^{\circ} \mathrm{C}$ to freeze the melt layer. When the melt refroze, the central annular region, comprising more than $60 \%$ of the bottom surface of the ice specimen, was perfectly bonded to the Plexiglas. The outer area had lifted slightly because of the expansion of the water on freezing. The gap between the ice and Plexiglas in this region was very small because Newton's interference rings were visible. The confining plates were then installed and a C-clamp with a Styrofoam pad was used to clamp the sample to the Plexiglas to prevent separation when water, at $0^{\circ} \mathrm{C}$, was poured in around the sides to fill the small $\sim 1-2 \mathrm{~mm}$ gap between the confining walls and the ice. These precautions were essential in preventing unwanted cracks in the bulk specimens during testing, due to improper bonding of ice to Plexiglas, which would block the view of the iceindentor interface.

The method of growing large single crystals of freshwater ice has been described before (Gagnon, in press). A container with insulated sides and bottom, filled partially with de-aired and de-ionized water, was placed in a cold room at $-10^{\circ} \mathrm{C}$. The top of the container was covered with cardboard except for an opening at one end of the rectangular container. Cold air blowing in through the opening at one end caused the growth of very long singlecrystal plates on the water surface. One of these continued to grow to take up the majority of the surface area, $20 \mathrm{~cm} \times 60 \mathrm{~cm}$. When a few centimeters' thickness of this ice had grown, it was removed from the container and the remaining water was discarded. In a room at $0^{\circ} \mathrm{C}$, the ice plate was then placed in the bottom of the empty container and degassed water at $0^{\circ} \mathrm{C}$ was added through a small hose placed under the ice plate. As the water entered, the ice floated on the surface preventing air from saturating the liquid. When $\sim 15 \mathrm{~cm}$ depth of water had been added, the container was put into the cold room at $-10^{\circ} \mathrm{C}$ which caused the gap between the ice edge and the sides of the container to freeze quickly, sealing the water completely from the air. The ice plate behaved as a template and grew in thickness primarily as one large single crystal with no bubbles. When the ice had grown to the desired thickness, it was removed from the container and a layer of a few centimeters' thickness was cut from its top surface to serve as a template for the next refill of the ice-growing container.

\section{DATA ANALYSIS}

Figure 4 shows the time-series records from the pressure and conductance sensors and the total load-time series from the load cell for a typical test. The total ice penetration was $\sim 1.7 \mathrm{~cm}$. Because of the symmetry of the confinement of the ice and its pyramid shape, most of the ice/platen contact occurred in the vicinity of the centrally located pressure/conductance sensor. The load and pressure records exhibit a sawtooth periodic breaking pattern often characteristic of ice crushing and indentation (Määttänen, 1983; Michel and Blanchet, 1983; Evans and others, 1984; Sodhi and Morris, 1984; Timco and Jordaan, 1988; Gagnon and Mølgaard, 1991; Gagnon and Sinha, 1991). In other work on ice

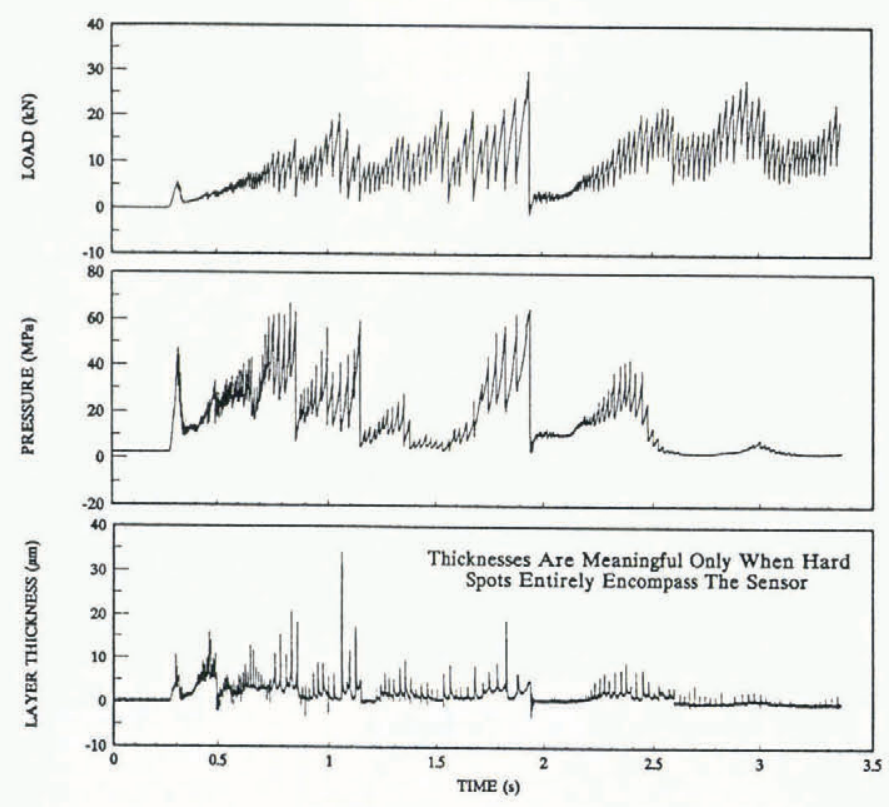

Fig. 4. Load, pressure and liquid-sensor records for a typical test run at $-10^{\circ} \mathrm{C}$ with a nominal actuator speed of $0.5 \mathrm{~cm} \mathrm{~s}^{-1}$. 
indentation (Gagnon and Mølgaard, 1991, Gagnon and Sinha, 1991; Gagnon, in press), evidence has been presented that indicates that as a result of the indentation and crushing process liquid water is produced. The conductance record confirms this, since it clearly shows that liquid is present as soon as contact occurs, and throughout the crushing phase which takes place after the first drop in load.

Figure 5 shows the same records on an expanded scale. The sudden drops in the load records are accompanied by rapid increases in the pressure and nominal liquid-layer thickness. Electrical signals generated by cracking of ice in the vicinity of the liquid sensor are also evident. These are distinguishable from signals associated with the presence of liquid by the fact that the electrical signals can be positive or negative, they occur at the beginning of the liquid-sensor signals and, as has also been reported by others (Fifolt and others, 1992), are very short in duration ( $<2 \mathrm{~ms}$ for single cracks). These characteristics were clear from signals generated during a test when no excitation was applied to the bridge circuit. A fuller discussion of this phenomenon will be given in a future paper. The spiked signals associated with liquid, on the other hand, are always positive and exhibit a decaying characteristic probably associated with the refreezing of liquid produced during load drops. The proper interpretation of the liquid-sensor and pressure data can be deduced from a careful analysis of the video record.

The video records invariably showed the same characteristics for tests where specimens were confined properly and bonded well to the Plexiglas plate. The region of contact consisted of a central zone where the ice appeared to be undamaged, because the crushing platen was clearly visible through it (Fig. 6), surrounded by a dense mixture of fine and coarse particles of ice that was opaque. This has also been observed by Gagnon and Mølgaard (1991) using a different apparatus. The integrity of the undamaged hard-spot ice has been verified by thin section analysis (Gagnon, in press). As

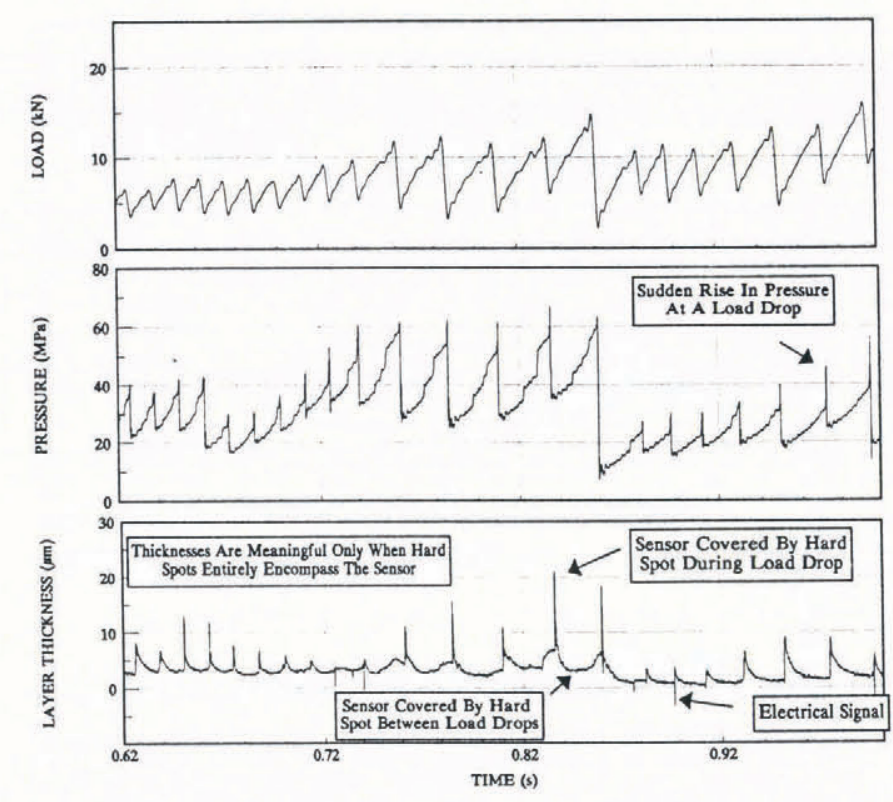

Fig. 5. Sections of the load, pressure and liquid-sensor records, on an expanded scale, for the test shown in Figure 4.

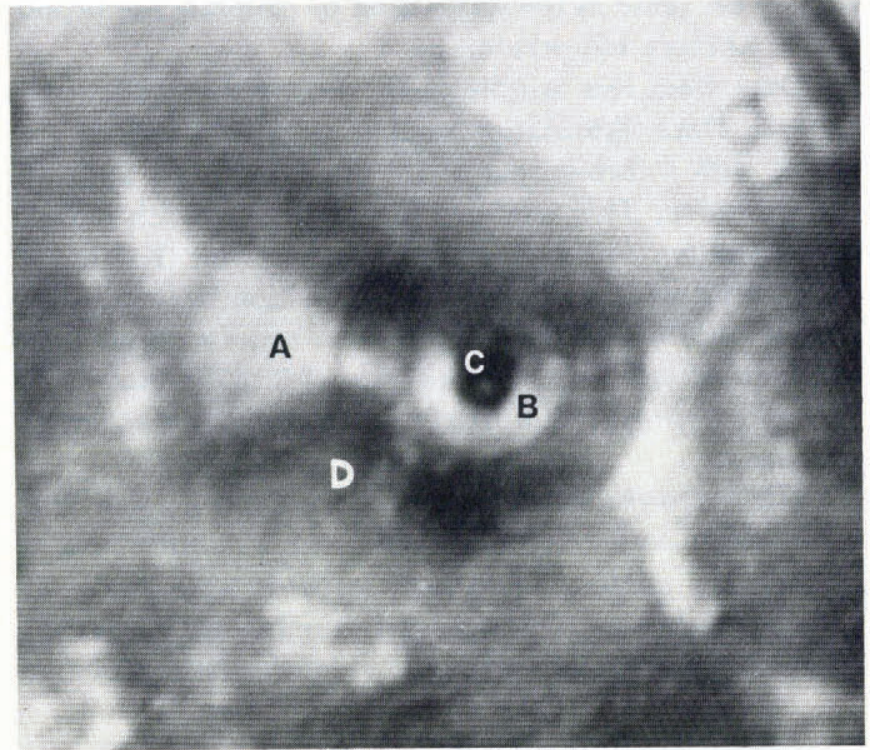

Fig. 6. Video frame showing the platen/ice contact zone during a crushing test. The transparent undamaged zone (A), which covers a fraction of the pressure-sensor piston (B) and marginally encompasses the liquid sensor $(C)$, bears approximately $88 \%$ of the load. It is surrounded by opaque material (D) consisting of small ice particles and partially refrozen extruded material from the high-pressure zone. The bright region in the upper righthand corner is light reflecting internally from the sloping surface of the specimen.

crushing occurred during a test, the contact region would change in shape, size and position.

The importance of the role of the transparent areas of contact has been noted and studied before (Riska and others, 1990; Fransson and others, 1991; Gagnon and Mølgaard, 1991; Gagnon and Sinha, 1991). Through analysis of pressure and load records, and contact-area measurements from similar tests using the same apparatus with the same type of ice, Gagnon (in press) has shown that $\sim 88 \%$ of the load is borne on the transparent hard spots. It was also shown that the spots grow in size with increasing load and that the pressure on them is $\sim 70 \mathrm{MPa}$ on the ascending part of the sawteeth and substantially greater on the sharp descending parts of the sawteeth.

Gagnon and Mølgaard (1991) introduced the mechanism of pressure melting and heat generation by flow of melt during the rapid load drops as a means of explaining the visual, load and displacement data from ice crushing. In this formulation, the pressure is high enough on the transparent areas to initiate pressure melting (Fig. 7). The thin layer of liquid which forms flows under the extreme pressure and generates heat from viscosity which goes into further melting. On moving towards the outer region of the high-pressure zones, the pressure is reduced and the melting temperature is elevated so that refreezing occurs by heat flow to the cold surrounding ice and metal. On leaving the highpressure zone the liquid has partially refrozen. This is consistent with several observations of refrozen liquid produced in indentation and impact on ice (e.g. Kheysin and Cherepanov, 1970; Gagnon and Mølgaard, 1991; Gagnon and Sinha, 1991). It is also consistent with temperature measurements (Gagnon and Sinha, 1991; 


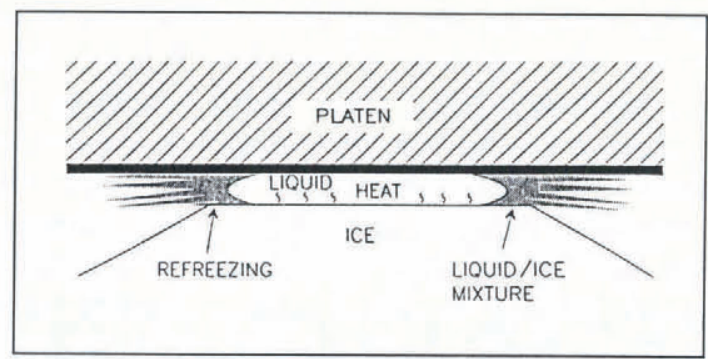

Fig. 7. Schematic of the process of pressure melting and viscous flow of melt which occurs when the ice moves against the platen. The relative velocity of the ice towards the platen is $\sim 0.14 \mathrm{~cm} \mathrm{~s}^{-1}$ on the ascending side of $a$ sawtooth and $\sim 26 \mathrm{~cm} \mathrm{~s}^{-1}$ on the descending side at a load drop. The fluid-layer thickness is on the order of $\mu m$.

Gagnon, in press), indicating temperature rises to $0^{\circ} \mathrm{C}$ at the platen/ice interface during crushing.

It is important to note that due to the size of the central pressure sensor, $0.5 \mathrm{~cm}^{2}$, and the size and irregular shapes of the transparent contact spots, that the sensor rarely, and then only marginally, was encompassed by the contact spot. The measured pressure was in fact an average pressure where the actual pressure was lower than average at the outer regions and higher than average at the center. A smaller pressure sensor would probably have recorded higher pressures when located in the center of a transparent contact spot. An average pressure of $\sim 70 \mathrm{MPa}$ is consistent with pressures required for pressure melting because a uniform layer of melt on a circularshaped transparent spot would imply a parabolic pressure distribution peaking to $140 \mathrm{MPa}$ at the center (Bowden and Tabor, 1986, p. 274), which is adequate for melting at $-10^{\circ} \mathrm{C}$.

The video records and the sensor data revealed that the size, shape and position of the transparent spots were determined by two mechanisms: the pressure melting and extrusion of liquid process and the spalling process. This is best described by considering what happens in a typical test from a trough in the load record to the next trough (Fig. 5). On the ascending side of the sawtooth, the transparent-spot area grew in size as the load increased while maintaining a stress of $\sim 70 \mathrm{MPa}$. The majority of the energy supplied by the testing apparatus went into elastic loading in the ice/apparatus system, since only a small amount of ice gets removed by the pressure-melting extrusion process on the ascending side of sawteeth. Approximately $0.3 \times 10^{-8} \mathrm{~m}$ of ice is removed for each Newton of accumulated load (Gagnon, in press). The elastic compliance of the ice/apparatus system, on the other hand, is $\sim 1 \times 10^{-8} \mathrm{~m} \mathrm{~N}^{-1}$. This represents the combined compliances of the ice/ice-holder system, $\sim 0.7 \times 10^{-8} \mathrm{~m} \mathrm{~N}^{-1}$ (Gagnon, in press), and the compliance of the actuator/hydraulic system, as determined from the displacement record of the actuator piston. Hence $\sim 77 \%$ of the actuator energy goes into elastic energy of the ice/apparatus as load increases during a test. Eventually, as the strain increased, the load on the ice reached a point where a large crack(s) occurred and a spall(s) broke away from the area of contact (Fig. 8). This led to a sudden rise in pressure and increase in liquidlayer thickness on the remaining ice (Fig. 5) and rapid release of the built-up elastic strain by movement of the

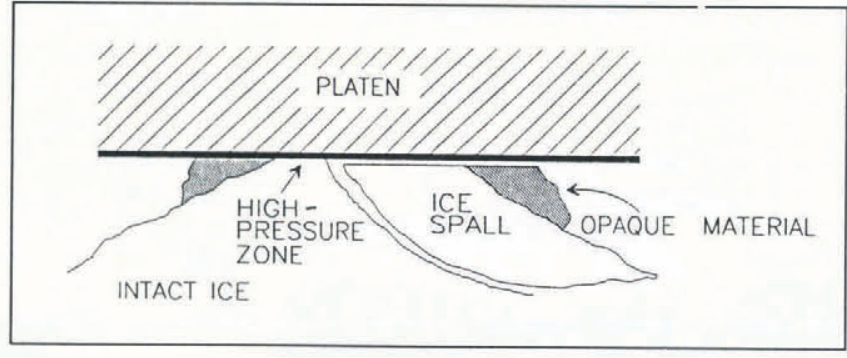

Fig. 8. Schematic of the spalling process that occurs at a load drop.

ice against the platen through rapid removal of ice via the pressure-melting and extrusion process (Fig. 7). The rapid movement continued until the consequent reduction in load, and increase in hard-spot area, reduced the pressure on the ice to that which was present on the ascending part of the sawtooth pattern, and the cycle started again. The compliance of the ice/apparatus system resulted in relative displacement rates of the ice and platen towards one another of $\sim 0.14 \mathrm{~cm} \mathrm{~s}^{-1}$ during increases in load, and $\sim 26 \mathrm{~cm} \mathrm{~s}^{-1}$ during load drops, even though the nominal actuator speed was $0.5 \mathrm{~cm} \mathrm{~s}^{-1}$ (Fig. 9).

Approximate values for the thickness of the liquid layer on both sides of the sawtooth can be calculated using an expression from the theory of squeeze films (Bowden and Tabor, 1986, p. 274), assuming a circular contact area,

$$
h=\left(3 \eta V R^{2} / 2 \bar{P}\right)^{\frac{1}{3}}
$$

where $h$ is the layer thickness, $\eta$ is the viscosity of water at $0^{\circ} \mathrm{C}\left(1750 \times 10^{-6} \mathrm{Pas}\right), V$ is the velocity of the ice moving against the platen $0.0014 \mathrm{~m} \mathrm{~s}^{-1}$ and $0.26 \mathrm{~m} \mathrm{~s}^{-1}$ for the ascending and descending sides of the sawtooth, respectively), $\bar{P}$ is the average pressure over the contact spot $(70 \mathrm{MPa})$ and $R$ is the radius of the spot $\left(0.94 \times 10^{-2}\right.$ and

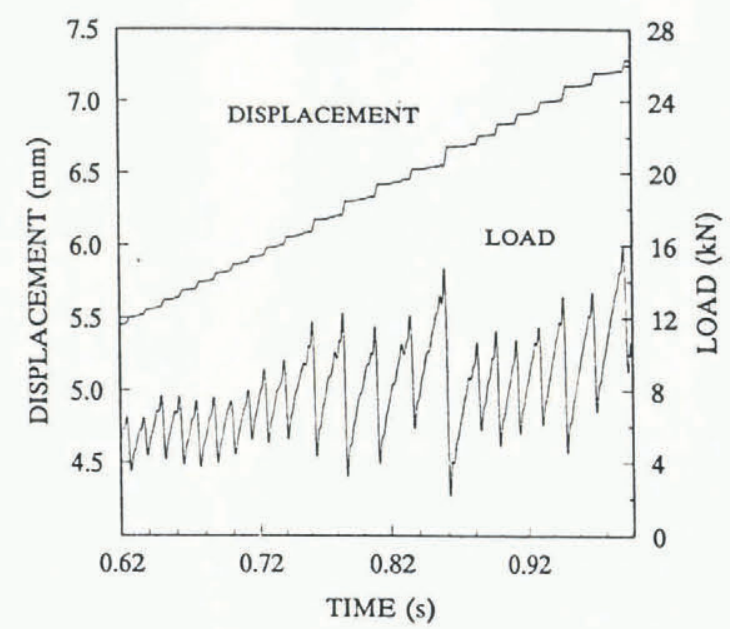

Fig. 9. Section of the time series of the relative displacement of the ice against the crushing platen, and corresponding load for the test shown in Figure 4. The time segment is the same as that in Figure 5. The relative displacement was determined from the nominal actuator speed, the load data and the known compliance of the icel apparatus system. For the purpose of presentation, the load record has been filtered to diminish resonance. 
Table 1. Layer-thickness measurements from the liquid sensor
Layer thickness for
ascending load

$\mu \mathrm{m}$

2.8

3.2

2.4

2.7

Mean 2.8
Layer thickness

at load drops

$\mu \mathrm{m}$

20.8

20.7

20.8 ice/platen interface, the data yield upper-limit measurements for the thickness of the liquid layer between transparent hard-contact areas and the crushing platen. The video records and trends and relationships in pressure, load, displacement and liquid-sensor records were consistent with the process of pressure melting and viscous flow of the melt introduced by Gagnon and Mølgaard (1991). A video system capable of 1000 frames $\mathrm{s}^{-1}$, or faster, would provide extremely valuable information about the spalling process and the evolution of the transparent hard spots during the rapid load drops.

The compliances of the testing apparatus and ice play an important role even in a stiff system.

\section{ACKNOWLEDGEMENTS}

The author is grateful to $\mathrm{Mr} \mathrm{T}$. Slade, who operated the testing frame during the test program.

\section{REFERENCES}

ing sides of the sawtooth, respectively (Gagnon, in press)). Using these values an average liquid-layer thickness of $1.7 \mu \mathrm{m}$ is obtained for the ascending side and $8.4 \mu \mathrm{m}$ for the descending side.

This can be compared with the actual measurement of layer thickness obtained from the conductance records. To do this, one must choose parts of the record that correspond to the times when the hard spot encompasses the conductance sensor, otherwise the sensor would also be measuring liquid content of the opaque material and give erroneous thickness values, biased toward higher values. Even though the video system was limited to 30 frames s $^{-1}$ and only occasionally were the hard spots positioned correctly over the sensor, there were enough video frames showing the hard spots marginally encompassing the sensor to obtain an upper limit for the true layer thickness. Table 1 gives the layer thickness for four instances in the records when the hard spots encompassed the sensor on ascending parts of the sawteeth in the load records, and two instances for the load drops. At no time did a video frame actually catch the spot at the precise instant of a load drop. However, a number of frames showing the spot encompassing the sensor before and after the load drop indicated that in those cases it was reasonable to assume the sensor was encompassed during the load drops. The average values for the layer thickness on ascending and descending parts of the sawteeth (2.8 and $20.8 \mu \mathrm{m}$, respectively) were, as expected, somewhat higher than the theoretical values because the sensor was only marginally encompassed by the transparent contact spots. It is also possible that electrical pulses due to spalling of ice biased liquid-thickness measurements at load drops by an additional value of $\sim 5 \mu \mathrm{m}$, based on the amplitude of negative electrical pulses in the records (Fig. 5). The measured liquid-layer thicknesses, then, represent upper limits for the actual thicknesses and cover a range that is consistent with the theoretical values.

\section{SUMMARY AND GONCLUSIONS}

A novel method has been used to detect the presence of liquid during crushing experiments on fresh-water ice. When analyzed in conjunction with video records of the
Bowden, F.P. and D. Tabor. 1986. The friction and lubrication of solids. Oxford, Clarendon Press.

Bradshaw, A. L. and K. E. Schleicher. 1980. Electrical conductivity of seawater. IEEE f. Oceanic Eng., OE-5(1), 50-62.

Evans, A. G. and 6 others. 1984. Indentation spalling of edge-loaded ice sheets. In International Association for Hydraulic Research. 7th International Symposium on Ice, Hamburg, ..., 1984. Vol. 1. Hamburg, Hamburgische Schiffbau-Versuchsanstalt GMbH, 113-121.

Fifolt, D. A., V.F. Petrenko and E. M. Schulson. 1992. Electrical signals

Fransson, L., T. Olofsson and J. Sandkvist. 1991. Observations of the failure process in ice blocks crushed by a flat indentor. In Muggeridge, D.B., D.B. Colbourne and H.M. Muggeridge, eds. POAC'91; the 11th International Conference on Port and Ocean Engineering under Arctic Conditions, September 24-28, 1991, St. John's, Canada. Proceedings. Vol. 1. St. John's, Memorial University of Newfoundland. Ocean Engineering Research Centre, 501-514.

Gagnon, R. E. In press. Generation of melt during crushing experiments on freshwater ice. Cold Reg. Sci. Technol.

Gagnon, R.E. and J. Mølgaard. 1991. Evidence for pressure melting and heat generation by viscuous flow of liquid in indentation and

Gagnon, R. E. and N.K. Sinha. 1991. Energy dissipation through melting in large scale indentation experiments on multi-year sea ice. In Ayorinde, O. A., N. K. Sinha, W. A. Nixon and D. S. Sodhi, eds. Proceedings of the 10th International Conference on Offshore Mechanics and Arctic Engineering, ..., Stavanger, Norway, June 23-28, 1991. Vol. 4. Arcticl polar technology. New York, American Society of Mechanical Engineers, 157-161.

Kheysin, D. Ye. and N. V. Cherepanov. 1970. Izmeneniye struktury l'da v zone udara tverdogo tela o poverkhnost' ledyanogo pokrova [Change of ice structure in the zone of impact of a solid body against the ice cover surface]. Probl. Arkt. Antarkt. 34, 79-84.

Määttänen, M. 1983. Dynamic ice-structure interaction during continuous crushing. CRREL Rep. 83-5.

Michel, B. and D. Blanchet. 1983. Indentation of an $\mathrm{S}_{2}$ floating ice sheet in the brittle range. Ann. Glaciol., 4, 180-187.

Riska, K., H. Rantala and A. Joensuu. 1990. Full scale observations of shipice contact. Espoo, Helsinki University of Technology. Laboratory of Naval Architecture and Marine Engineering. (Report M-97.)

Sodhi, D.S. and C.E. Morris. 1984. Ice forces on rigid, vertical, cylindrical structures. CRREL Rep. 84-33.

Timco, G. W. and I.J. Jordaan. 1988. Time series variations in ice crushing. In Sackinger, W. M. and M. O. Jeffries, eds. Port and ocean engineering under Arctic conditions. Vol. 1. Fairbanks, AK, University of Alaska. Geophysical Institute, 13-20.

The accuracy of references in the text and in this list is the responsibility of the author, to whom queries should be addressed. from cracks in ice. In Maeno, N. and T. Hondoh, eds. Physics and chemistry of ice. Sapporo, Hokkaido University Press, 470-475. impact experiments on ice. Ann. Glaciol., 15, 254-260. 